\title{
Research on the Modes and Paths of Transformation of Scientific and Technological Achievements of Colleges and Universities in Guangdong-Hong Kong-Macao Greater Bay Area
}

\author{
Jian Dong ${ }^{1}$, JianRu Xie ${ }^{2}$, HuaShan Pan $^{3 *}$ \\ ${ }^{1}$ School of Management, Guangdong Food and Drug Vocational College, Guangzhou, China \\ ${ }^{2}$ School of Accounting Department, Guangdong Polytechnic of Water Resources and Electric Engineering, \\ Guangzhou, China \\ ${ }^{3}$ Office of Academic Research, Guangdong Food and Drug Vocational College, Guangzhou, China \\ *Corresponding author. Email:13524919@qq.com
}

\begin{abstract}
Against the backdrop of the reality of the transformation of scientific and technological achievements in domestic colleges and universities, this paper summarized the common modes and major paths of the transformation of scientific and technological achievements in colleges and universities in Guangdong-Hong Kong-Macao Greater Bay Area (GBA). On the strength of the analysis of the issues and hindrances during the transformation, this paper explored the improvement of the modes and paths of the transformation of scientific and technological achievements. Besides, the specific countermeasures and suggestions were also proposed in this paper for the purpose of providing useful reference for promoting the effective transformation of scientific and technological achievements in the colleges and universities in the GBA.
\end{abstract}

Keywords: colleges and universities, transformation of scientific and technological achievements, modes and paths

\section{INTRODUCTION}

The Guangdong-Hong Kong-Macau Greater Bay Area (GBA), planned to be built into an International Scientific and Technological Innovation (STI) Center, represents one of the regions with the highest degree of openness and the strongest economic vitality in China. Besides, it is also reputed as a vital strategic position in the overall national development. As one of the essential subjects of the national innovation system, colleges and universities, in particular, are entrusted with heavy responsibilities in innovation concerning knowledge and technology. More than that, serving as one of the innovation subjects with the closest connection with industry enterprises, colleges and universities are further expected to take the reform of research methods as the strategic pivot of its transformation and development, so as to improve the efficiency in transforming achievements. Colleges and universities, more precisely, shall promote the industrial transformation in the new era and perform the role of innovation resources in driving the innovation of the whole society, with the aim of better serving the industrial development and the economic transformation and upgrading in the GBA. According to the China Patent Survey Report in 2020 released by China National Intellectual Property Administration, the implementation rate of effective patents in colleges and universities nationwide is $11.7 \%$, accounting for only $1 / 5$ of that in China $(57.8 \%)$. The industrialization rate of effective patents is $3.0 \%$, representing only $1 / 14$ of that in China $(41.6 \%)$. The effective patent transfer rate is $3.6 \%$, and the effective patent grants rate is $4.4 \%$. It can be seen that colleges and universities, even if they are gathering a large number of STI talents and acting as the driver of innovation, still have obvious weaknesses in the transformation of scientific and technological achievements. In this case, it is of great significance to transform the scientific and technological achievements of colleges and universities for application, accelerate 
the transformation efficiency of scientific and technological achievements, and thus promote the industrial transformation in the new era, for the sake of the scientific and technological and economic development in the GBA.

\section{COMMON MODES OF TRANSFORMATION OF SCIENTIFIC AND TECHNOLOGICAL ACHIEVEMENTS OF COLLEGES AND UNIVERSITIES IN THE GBA}

The transformation modes of scientific and technological achievements of colleges and universities in the GBA generally include transformation by selfinvestment, technology transfer and licensing, collaborative transformation by technology investment, collaborative research and development (R\&D), and transformation by introduction of technical achievements.

\subsection{Transformation by Self-investment}

According to the documents such as Opinions on Personnel Management Issues in Relation with Encouraging Scientific Researchers of Universities and Research Institutes for Entrepreneurship and Innovation issued by Guangdong Province in 2017, researchers in colleges and universities are allowed to pursue entrepreneurship and innovation in enterprises with their scientific research projects and achievements, or start their own businesses on the strength of their own professional knowledge in the manner of quitting their current positions. For example, Sun Yat-sen University directly incubated Da An Gene Co., Ltd. of Sun Yat-sen University, a biomedical high-tech enterprise; Professor Zhou Guofu's team from South China Normal University founded Shenzhen Guohua Optoelectronic Tech. Co., Ltd.; and Lu Shenglin, an off-post teacher from Dongguan University of Technology, founded OPT Machine Vision Tech Co., Ltd. [1].

\subsection{Technology Transfer}

The contract turnover in respect of transformation by transfer, licensing and evaluation investment in Guangdong colleges and universities from 2017 to 2019 is RMB 189 million, RMB 320 million and RMB 944 million respectively, with a sustained high growth in contract turnover. The scale of transformation of scientific and technological achievements also enjoy a sustained growth, along with the impressive performance of large transformation contracts. In the past three years, there were 12 transformation contracts of individual scientific and technological achievement exceeding RMB 20 million; 20 contracts exceeding
RMB 10 million; and 26 contracts exceeding RMB 5 million. The total amount of transformation contracts of scientific and technological achievements over RMB 5 million accounts for $34.93 \%$ of the turnover. In particular, the contract amount of Jinan University concerning transformation of patent by transfer, licensing and evaluation investment exceeds RMB 438 million in 2019, ranking the 3rd among national colleges and universities and the first among Guangdong colleges and universities, and exceeding the contract turnover of transformed scientific and technological achievements of Guangdong colleges and universities (RMB 2.048 billion) by $21.39 \%$. The contract turnover of Southern University of Science and Technology (SUSTech) with regard to the transformation of patent by transfer, licensing and evaluation investment exceeds RMB 334 billion in 2019.

\subsection{Collaborative Transformation by Technology Investment}

Colleges and Universities in Guangdong Province have practiced and explored a lot in respect of collaborative transformation by technology investment. For example, the collaboration between South China Agricultural University and Wens Group by way of technology investment improves the scientific research level of universities and the innovation of modes of talent cultivation, while expanding the scientific research capacity and overall strength of the enterprise. In the wake of the further reform of technology investment in the operational field of Guangdong Province of late years, a large number of technologies in colleges and universities have been successfully transformed through technology investment, generating the share income over several hundred million.

\subsection{Collaborative Research and Development}

The turnover of horizontal contracts of Guangdong colleges and universities from 2017 to 2019 is RMB 2.240 billion, RMB 2.529 billion and RMB 3.094 billion respectively, maintaining a stable growth trend; Zhongshan University has 2,169 regular service targets in three years from 2017 to 2019; South China Agricultural University has 500; Guangdong Pharmaceutical University has 122; Zhongkai University of Agriculture and Engineering has 119; and South China University of Technology has 77. By the end of 2019, SUSTech, in particular, has generated substantial cooperation with more than 350 enterprises, with the total funding for horizontal projects exceeding RMB 365 million. More precisely, more than 150 new horizontal collaborations were carried out by SUSTech in 2019, with the value of newly launched contract 
exceeding RMB 124 million, of which there are 22 individual contracts with a contract value of more than RMB 1 million.

\section{MAIN PATHS FOR TRANSFORMATION OF SCIENTIFIC AND TECHNOLOGICAL ACHIEVEMENTS OF COLLEGES AND UNIVERSITIES IN THE GBA}

The major paths for colleges and universities in the GBA to promote the transformation of scientific and technological achievements are generally to industrialize the scientific and technological achievements of universities by means of transformation platform, science and technology commissioner and matchmaking service, with the support of government resources and around the demands of enterprises and industries.

\subsection{Actively Extending the Transformation Chain of Scientific and Technological Achievements and Speeding up the Ability of Internal Transformation}

Ten high-level universities, such as Sun Yat-sen University, Jinan University and Guangdong University of Technology, have increased the direct investment in the transformation of scientific and technological achievements by focusing on building technology transfer centers, high-tech incubators and high-tech parks, so as to rapidly promote the transformation of scientific and technological achievements. For example, the High-tech Park of Sun Yat-sen University is a national incubator of high-tech enterprises (recognized by the Ministry of Science and Technology, PRC); the High-tech Park of Jinan University is a cultivation unit of national incubator of high-tech enterprises (recognized by the Ministry of Science and Technology, PRC); and the Innovation Valley of Guangdong University of Technology has been awarded as the "Demonstration Base of National Start-ups Incubator" (recognized by the Ministry of Human Resources and Social Security, PRC), the "National-level Maker Space" (recognized by the Ministry of Science and Technology, PRC), "National Entrepreneurship and Innovation Base for Practice and Cultivation in Colleges and Universities" (recognized by the Ministry of Education, PRC) and "National Demonstration Park for Colleges Students' Entrepreneurship" (recognized by the Central Committee of the Communist Youth League of China). Nearly 100 excellent scientific and technological achievements have been transformed on these platforms every year [2].

\subsection{Co-building New $R \& D$ Institutions to Further Facilitate the Innovation of Industrial Technology}

On the strength of resources from all walks of life and relying on different new R\&D institutions, local research institutes and other comprehensive transformation platforms for scientific and technological achievements, colleges and universities carry out allround matchmaking with industrial clusters such as cities, high-tech zones and professional towns, with its access to primary levels, and thus widely promote the industry-university-research (IUR) collaboration and the transfer and transformation of innovation achievements. There are also universities and colleges jointly build $R \& D$ institutions with enterprises, such as engineering research centers, industrial design centers, enterprise technology centers, key laboratories and other innovation platforms. On the grounds of the precedent transformation of scientific and technological achievements, colleges and universities innovate diverse conditions required during the process of transformation of scientific and technological achievements. It not only has promoted the direct transformation of relevant technical achievements of scientific research teams in cooperative enterprises, but also will promote the continuous transformation of subsequent achievements of teams.

\subsection{Selecting Talents for Station to Support the Transformation and Upgrading and Innovative Development of Industries}

The scientific research is directly conducted at the front line of production by selecting scientific special commissioners to be stationed in enterprises, and cobuilding the R \& $\mathrm{D}$ center between the universities and enterprises. For example, South China University of Technology has sent more than 700 scientific special commissioners to more than 1,000 enterprises in Guangdong, facilitating the STI accomplished in the production line. This traditional "one-to-one" IUR matchmaking mode may promote the direct transformation of relevant technological achievements of scientific research teams of colleges and universities in cooperative enterprises, effectively strengthen the close interaction between disciplines and industries, and finally promote the transformation and upgrading and innovative development of local pillar industries.

\subsection{Introducing Service Platform for Science and Technology to Perform Transformation and Matchmaking of Achievements}

Relying on different types of online and offline trading markets of technological achievements along 
with promoting matchmaking services, such as previous China Hi-tech Fair, Guangdong Matchmaking Meeting of Scientific and Technological Achievements and Industry, China International Applied Science \& Technology Expo, and different online platforms including databases of scientific and technological achievements, transactions and services technology and intellectual property, the transfer and transformation of achievements is achieved. Take the construction of South China Technology Commercialization Center for Instance. Guided by the transformation concept of "Internet+", the network platform for technology trading is established, in furtherance of building a transformation hub connecting service institutions of technology transfer, investment and financing institutions, colleges and universities, research institutes and enterprises, and thus realizing the interconnection of the scientific and technological achievements resources in the GBA.

\section{THE HINDRANCES TO THE TRANSFORMATION OF SCIENTIFIC AND TECHNOLOGICAL ACHIEVEMENTS OF COLLEGES AND UNIVERSITIES IN THE GBA}

\subsection{No Practical Policies in Relation to Achievement Transformation yet}

Following a series of policies and regulations issued from the national level, a large number of reforms have been carried out in decentralizing the right to use, dispose of and benefit from scientific and technological achievements. The Notice of the China National Property Administration on Further Strictly Regulating Patent Application, in particular, clearly states that, "Efforts should be made to guide the quantity and quality of patent applications to adapt to the level of regional economic development, industrial development needs and STI capabilities. Diverse performance measures shall be rationally set, in order to strengthen quality orientation, and give full play to the leading role of high-quality development indicators". The Regulations on Promoting the Transformation of Scientific and Technological Achievements in Guangdong Province has also broken through many original institutional hindrances to the transformation of scientific and technological achievements from the macro-policy level. However, there is still no complete laws and regulations on the IUR collaboration in colleges and universities. Accordingly, in the course of IUR collaboration, there will be some defects in the distribution of benefits, the division of responsibilities, the division of shares, etc., resulting in the collaboration not reaching the expected value for a long time.

\subsection{Insufficient Investment in the Transformation of Scientific and Technological Achievements in Colleges and Universities}

The uncertainty of scientific research output makes university researchers get less funds and support from the government and the market. Except Sun Yat-sen University, South China University of Technology, Jinan University and other first-class universities and key colleges and universities, universities have invested relatively insufficient resources in the transformation of scientific and technological achievements. The prime assessment for scientific research projects in colleges and universities are patents and papers, but whether the results can be transformed, whether the transformation matches the scientific research, technological development, and the market demand, and how mature the scientific and technological achievements produced are not the focus of assessment. Researchers in colleges and universities are keen to obtain governmental support for projects, publish papers, obtain awards and titles from the government, and then complete the assessments in colleges or universities and promote their professional titles. They do not pay attention to whether it can be transformed and how much it can be transformed, with insufficient investment to the transformation of achievements [3].

\subsection{Mismatching of Supply and Demand Between Enterprises and Colleges and Universities}

Colleges and universities shoulder the heavy responsibilities of teaching, scientific research and discipline construction, with importance attached to scientific research itself. Its scientific and technological achievements are managed as state-owned assets, but the right to dispose of and benefit from them is not granted to colleges and universities. Colleges and universities do not have the autonomy in the transformation of scientific and technological achievements and technology transfer. Besides, they lack the awareness and motivation to participate in the IUR collaboration and serve enterprises. There are institutional obstacles for enterprises and social capital to enter the incubation of scientific and technological achievements in colleges and universities. There are frequent occasions that universities have difficulty in finding suitable enterprises to transform their achievements and enterprises cannot find solutions to technical problems. Therefore, it is urgent to establish a professional, market-oriented and authoritative trading platform for scientific and technological achievements in the GBA. The platform is expected to summarize and release information relating to scientific and technological achievements and also provide colleges 
and universities with listed trading and publicity of scientific and technological achievements, as well as professional intermediary services, thus solving the problems of trading circulation and market-oriented pricing of achievements.

\subsection{Deficiencies in the Evaluation System of Scientific and Technological Achievements}

There are many factors involved in measuring the value of patent technology in colleges and universities, and it is difficult to build a standardized evaluation system. Some problems in the practice of patent technology transfer in colleges and universities include information asymmetry and difficulty in evaluation, which greatly restrict the transformation efficiency of scientific and technological achievements in colleges and universities. Patent evaluation involves Patent Studies, Accounting, Engineering Technology, Law and many other sciences, involving abundant knowledge. The current evaluation institutions in the GBA market is inadequate, and the quality of practitioners is uneven, leading to the nonstandard practice in the evaluation, unscientific appraisal, and inaccurate data. Besides, the organization and management of patent evaluation are relatively lagging behind; there is no open platform for patent transactions; and the flow of information such as technological achievements and market demand is passive in a narrow range. However, according to the survey data in the Annual Report on the Transformation of China's Scientific and Technological Achievements in 2018, only $9.5 \%$ of the total scientific research institutes in colleges and universities in China have set up institutions specialized in technology transfer and transformation. It proves that there is a lack of evaluation of the value of patented technology in colleges and universities.

\subsection{Poor Financing Channels in Colleges and Universities}

The government encourages scientists and engineers perform direct transformation of scientific and technological achievements and incubate scientific and technological enterprises. However, in the middle and late stages of industrialization of scientific and technological achievements, the guiding role of government funds for improvement cannot be well played. High-tech enterprises incubated by colleges and universities occupying shares are bound by the preservation and appreciation of state-owned assets, and thus often miss the best period of capital financing. The interests of most competent departments are not consistent with the that of colleges and universities during the transformation of scientific and technological achievements. Top-down policies tend to be decomposed layer by layer. The divergent management concepts also make the external capital, especially the venture capital, enter the incubator of scientific and technological achievements in colleges and universities with obstacles, thus leading to a large capital gap for the transformation of scientific and technological achievements. The shortage of funds and financing difficulties directly lead to a serious low transformation rate of scientific and technological achievements.

\section{IMPROVEMENT OF THE TRANSFORMATION MODES AND PATHS OF SCIENTIFIC AND TECHNOLOGICAL ACHIEVEMENTS OF COLLEGES AND UNIVERSITIES IN THE GBA}

\subsection{Strengthening the $R \& D$ Orientation of Science and Technology}

Colleges and universities should further improve the classified assessment mechanism, and guide scientific and technological personnel to give priority to teaching, scientific research and transformation, while refining the division of labor and collaboration. Along with applied research targeting domestic and foreign market needs, colleges and universities should take the initiative to go to the market, and improve the weight of horizontal projects entrusted by enterprises as the appraisal of scientific research performance. To strengthen the market orientation of the project, and the science and technology management department, amid the establishment and top-level design of applied R\&D projects, shall take the needs of enterprises as the leading factor, with promoting the transfer and transformation of scientific and technological achievements as the core, and closely focusing on industrial development, especially for those emerging industries.

\subsection{Intensifying the Innovative IUR Collaboration}

On the strength of IUR collaboration among "Three Ministries and Two Institutes" (i.e. Ministry of Science and Technology, Ministry of Education, Ministry of Industry and Information Technology, Chinese Academy of Sciences) in Guangdong Province, the innovative IUR collaboration shall be further intensified, with the enhanced policy support and guidance. Colleges and universities are encouraged to maintain the regular and long-lasting collaborative relationship, along with actively promoting different modes of collaboration by technology investment, so as to strengthen the in-depth and close collaboration including further R\&D of technical achievements, industrialization of technical achievements, exchange 
and cooperation among talents and sharing of equipment, and thus finally improve the efficiency and quality of transformation of scientific and technological achievements. It is suggested to give full play to the advantages of scientific research institutions close to the market and industry, and actively strengthen the key role and service capacity of provincial scientific research institutions in the maturation and industrialization of scientific and technological achievements. Besides vigorously promoting the division of labor and collaboration between scientific research institutions and colleges and universities in the course of transformation of scientific and technological achievements, it is also suggested to explore the establishment of a model mechanism for sharing and collaborative transformation of achievements of colleges and universities in the GBA, for the purpose of accelerating the evolution from fundamental applied research to the industrialization of achievements by shortening the transformation cycle of achievements.

\subsection{Improving Supporting Measures and Rules}

It is suggested to further publicize policies such as Regulations on Promoting Transformation of Scientific and Technological Achievements in Guangdong Province and Notice of the China National Property Administration on Further Strictly Regulating Patent Application, in order to enhance the understanding and knowledge of scientific researchers. Besides, qualified colleges universities and scientific research institutions shall attempt to formulate relevant rules and operation procedures for the right of independent disposal of the unit's achievements, technology investment, etc., and share advanced experiences and practices. In respect of the disposal of and the right to benefit from the intangible assets such as scientific and technological achievements made while holding position in the unit, as well the equity and dividend incentives, the operational guidelines shall be formulated at the first opportunity while clarifying the relationship between different policies. Under systematic coordination, different departments of state-owned assets, discipline inspection, finance, taxation, and audit shall comprehensively unify their knowledge and understanding of the existing policies, and thus avoid the situation of mutual contradiction hindering the implementation. In a word, for the main body of scientific and technological achievements transformation in colleges and universities, we should support the principle that "all is permissible unless prohibited".

\subsection{Improving the Investment and Financing System of Science and Technology}

It is recommended to set up a financial fund for transformation of scientific and technological achievements and establish a mechanism for organizing scientific and technological projects oriented to the transformation of scientific and technological achievements. Besides, while giving full play to the key role of the government, the transformation of scientific and technological achievements shall be accelerated in response to the advanced but immature scientific and technological achievements of colleges and universities aside from the reality that enterprises are reluctant to invest and bear risks. The venture capital mechanism of achievement transformation shall be improved. The leveraging role of government fund shall be played in continuously attracting social capital, and the qualified technology transfer institutions are expected to cooperate in establishing investment funds, for the purpose of sharing the risk of transformation. The pilot test shall be conducted for accelerating the maturation of achievements and the rate of successful achievement transformation shall be thus increased[4].

\subsection{Establishing Multi-Index Assessment and Evaluation System}

The performance evaluation system shall be improved while taking social benefits generated from the actual application of research results as an important index. The multi-index performance assessment standards shall be applied to generate objective evaluation of college scientific researchers, and different management and assessment modes shall be implemented for staff engaged in basic research and applied research with regard to their respective labor and division of labor. Besides, a reasonable incentive mechanism shall be established to motivate the person engaged in the transformation of scientific and technological achievements by increasing the reward of transformation income and promoting professional title appraisal, etc. In 2019, the cash and equity income obtained from the transformation of scientific and technological achievements by means of transfer, licensing and evaluation investment in SUSTech was rewarded to researchers as high as RMB 236 million.

\subsection{Strengthening the Construction of Service System of Science and Technology}

The development of IUR collaboration shall be strengthened. The "two corridors plus two points" structure system of STI corridors of GuangdongShenzhen-Hong Kong and Guangdong-Zhuhai-Macao, and STI poles of Shenzhen-Hong Kong Hetao and 
Guangdong-Macao-Hengqin shall be improved. We shall also promote the construction of comprehensive national science centers and strengthen the construction of technology transfer institutions in colleges and universities. The qualified colleges and universities are expected to deepen the internal construction of technology transfer institutions, improve the institutional mechanism, and enhance the incubation capacity of achievements. Additionally, the construction of technical brokers shall be strengthened, so as to improve the service network, give full play to professional advantages, and accelerate the transformation of scientific and technological achievements in colleges and universities. Besides, the communication and cooperation with industrial enterprises, associations and social professional technology transfer institutions shall be actively strengthened, followed by the construction of the feedback mechanism of scientific research information for market demand, and the streamline process of market-oriented scientific research projects. As a result, the research quality of scientific and technological projects will be finally upgraded.

\section{CONCLUSION}

The rapid development of science and technology and the high-level transformation of scientific and technological achievements will be an important driving force for the GBA construction. Following the gradual implementation of China's series of policies and regulations in relation to the facilitation of the transformation of scientific and technological achievements, the transformation of scientific and technological achievements and the construction of the national technology transfer system have made positive progress. The transformation of scientific and technological achievements in universities involves many links in fields of science and technology, education, economic and society, and also many subjects such as universities, government, enterprises and funds, etc. It is a complex system project, which requires innovation of system and mechanism to promote organic synergy of innovation subjects and optimal allocation of innovation factors. The colleges and universities should expand their way of thinking along with the constant changes of their own scientific research situation, transformation qualification of scientific advances, researchers' individual conditions and the budgets of scientific research. Specifically, colleges and universities shall reform the scientific research management system, upgrade the transformation level, and implement multiple transformation modes and paths in collaboration, so as to enhance the transformation efficiency of scientific and technological achievements, and transform the achievements with practical value into productivity. This is of great significance for promoting the development of science, technology and economy, etc. in the GBA [5].

\section{ACKNOWLEDGMENTS}

This paper is a research project of Guangdong Provincial Education Science "Thirteenth Five-Year Plan" in 2020, "Research on the Modes and Paths of Transformation of Scientific and Technological Achievements of Colleges and Universities in Guangdong-Hong Kong-Macao Greater Bay Area" (2020GXJK247), and one of the milestones of the "Double-high Plan" project "Service and Innovation Center of Science and Technology Resources Sharing" (SG03-02.6) of Guangdong Food and Drug Vocational College.

\section{REFERENCES}

[1] Liu Yang, Wei Wenqiu, Feng Chunsheng, Lin Xiong. (2019) Research on the Status, Problems and Countermeasures of Transformation of Scientific and Technological Achievements in Universities and Research Institutes in Guangdong Province. Science and Technology Management Research, 39(02): 91-97.

[2] Yuan Chuansi, Jia Xiao, Yuan Lixin. (2020) Exploratory Research on the Implementation Modes and Paths of Transformation of Scientific and Technological Achievements in Universities. Science and Technology Management Research, 40(03): 84-89.

[3] Jiang Hai, Zi Hongzhi. (2015) Exploration and Practice of Collaborative Innovation Model for Transformation of Scientific and Technological Achievements in Universities in Guangdong. Science and Technology Management Research, 35(16): 94-99.

[4] Hu, Shujuan. (2019) Research on the Current Problems and Countermeasures of Patent Transformation in Research Institutes of Universities in Qinghai Province. Science \& Technology Information, 17(12): 186-188.

[5] Zhong Jiatao. (2016) Adopting Information Technology Means to Enhance the Effective Use of Technical Resources in the Transformation of Scientific and Technological Achievements. Modern Industrial Economy and Informationization, 16: 95-97. 